\title{
Predictors of Failed Laparoscopic Appendectomy in Perforated Appendicitis
}

\author{
Sean Martin, D.O.*, Yijin Wert, B.S.*, Zach Lyon, M.S. ${ }^{\dagger}$, Leonardo Geraci, D.O.* \\ *PinnacleHealth System, Department of General Surgery, Harrisburg, \\ ${ }^{\dagger}$ Lake Erie College of Osteopathic Medicine, Lake Erie, PA, USA
}

Correspondence to:
Sean Martin, D.O.
PinnacleHealth System,
Department of General Surgery,
Harrisburg, 4300 Londonderry
Rd, Harrisburg, PA 17109, USA
Tel: +1-610-248-3508
Fax: +1-717-657-7555
E-mail:
semartin@pinnaclehealth.org

semartinepinnaclehealth.org

Received May 16, 2017, Revised November 22, 2017, Accepted December 1, 2017

Purpose: A recent internal review of a community-based hospital system revealed a 19.19\% rate of conversion from a laparoscopic appendectomy to an open procedure. This study examined the preoperative risk factors for failed laparoscopic appendectomy requiring a conversion to a laparotomy.

Methods: A total of 198 patients presented with perforated appendicitis. Perforation was defined as a computed tomography (CT) scan interpretation, pathology findings, or surgical findings. Of these patients, 161 underwent a laparoscopic appendectomy or laparoscopy converted to an open procedure. The preoperative risk factors in the two groups were compared through a retrospective chart review.

Results: Through multivariant analysis, age greater than 45 was the greatest risk factor for the need to convert to an open procedure with an odds ratio (OR) of 3.51. A CT scan read of perforation was associated with a significant $2.65 \mathrm{OR}$. The C-reactive protein was $19.82 \mathrm{mg} / \mathrm{L}$ in the failed laparoscopic cases and $9.96 \mathrm{mg} / \mathrm{L}$ in the laparoscopic cases.

Conclusion: Patients older than 45 years old with a CT radiologist's read of a perforation in multivariant analysis have an increased risk of failed laparoscopic surgery requiring conversion to open surgery. (J Acute Care Surg 2018;8:59-64)

Key Words: Appendicitis, Laparoscopic appendectomy, Failed laparoscopic, Open appendectomy, Perforated appendicitis

Copyright $(2018$ by Korean Society of Acute Care Surgery

(c) This is an Open Access article distributed under the terms of the Creative Commons Attribution Non-Commercial License (http://creativecommons.org/licenses/by-nc/4.0) which permits unrestricted non-commercial use, distribution, and reproduction in any medium, provided the original work is properly cited.

ISSN 2288-5862(Print), ISSN 2288-9582(Online)

https://doi.org/10.17479/jacs.2018.8.2.59

\section{Introduction}

Appendicitis is the most common surgical ailment encountered by the acute care surgeon. With continued advancement in research, the treatment algorithm is continually challenged in regard to standard of care. While treatment options such as nonoperative management combined with antibiotics and percutaneous drainage of intra-abdominal abscess with interval appendectomy are studied, many still find early appendectomy to be standard of care.

Studies have shown that an appendectomy can be safely and effectively performed through either an open or laparoscopic approach. As laparoscopic training has become a foundation of general surgery residency, laparoscopic appendectomy (LA) has become the preferred approach for most surgeons. While LA is often successful, more challenging cases may require conversion to an open laparotomy (LCO). This study aims to identify risk factors for patients with perforated appendicitis for whom LA 
is likely to fail.

\section{Methods}

Institutional review board permission was granted for creation of a perforated appendicitis database. A search of patients through the PinnacleHealth System, comprising three hospitals (one urban, two communities) was performed. A total of 198 patients from February 25th 2010 to February 25th 2015 were identified based on the International Classification of Diseases (ICD)-9 code "perforated appendicitis." This code could be assigned from the diagnosis of perforation based on: final pathologic description or gross surgical finding in operative report. This data set encompasses all age groups. One patient was excluded as his perforation was due to penetrating abdominal trauma.

Of the remaining 197 patients in the database, 37 were removed from the dataset as they were taken to the operating room for open appendectomy and no laparoscopic procedure was attempted. The remaining 160 patients' charts were then reviewed and divided into LA and cases of LCO.

Data collection was performed using Siemen's Medical Soarian Document Management system which allowed for access to ED PulseCheck (Harris PulseCheck, Rosemont, IL, USA) emergency room records, Soarian Surgical Services documentation, surgeons dictated operative reports, handwritten daily progress notes and dictated radiology and pathology reports. Demographic data was obtained from emergency room records; past medical and surgical history were obtained from a combination of emergency room reports, history and physical and previous admissions. If a discrepancy in past medical history was found in charting, that comorbidity was excluded. Vital signs were collected from the first set taken by the emergency room intake nurse. American Society of Anesthesiologists (ASA) class was defined by the anesthesiologist who evaluated the patient preoperatively. Physical exam data was excluded as it was often incomplete and there was often a discrepancy between emergency room documentation and admitting history and physical.

Raw data was then submitted to an in-house biostatistician who first performed a univariate analysis. From this analysis, any risk factor with a $\mathrm{p}$-value $<0.1$ was entered into a multivariate analysis. Any of the data sets where greater than $50 \%$ were missing values were excluded from the multivariate analysis. A p-value of $<0.05$ was significant in both analysis.

\section{Results}

\section{Univariate analysis (Table 1)}

\section{1) Demographics}

No statistically different risk factors were seen when comparing the gender, ASA class, sepsis criteria met or onset of symptoms. Mean age for LA was 41.51, whereas LCO was $52.74(\mathrm{p}=0.0009)$. Overall median age was 42 , therefore the cohorts were subdivided by age with a cutoff of 45 years of age. In LCO cases $76.9 \%$ of cases were greater than 45 and in LA cases $45.9 \%$ were less than $45(\mathrm{p}=0.0007)$. While preoperative imaging was not ordered on all patients, a preoperative computed tomography (CT) read of perforation was found in $33.3 \%$ of LCO whereas it was only found in $13.9 \%$ of LA ( $\mathrm{p}=0.0068)$.

\section{2) Vital signs}

No one vital sign was found to have a statistically significant difference between LCO and LA. The mean temperature, heart rate, and respiratory rate of both groups did not meet systemic inflammatory response syndrome criteria as defined by the 2012 international consensus on sepsis. When combining vital signs with the patient's white blood cell (WBC) to define sepsis, the difference in the two groups also did not reach statistical significance with $50.0 \%$ of LA classified as septic and $64.1 \%$ of LCO cases meeting sepsis criteria $(\mathrm{p}=0.124)$.

\section{3) Comorbid conditions}

Common medical comorbid conditions were included in data collection, including: hypertension, hyperlipidemia, diabetes, coronary artery disease, chronic kidney disease and chronic obstructive pulmonary disorder. Of these, only hypertension was found to be of clinical significance with $46.2 \%$ of LCO cases carrying the diagnosis whereas hypertension was found in $28.7 \%$ of LA cases $(\mathrm{p}=0.0433)$. Surgical history for all patients was also reviewed and no significant difference was seen in patient's that 
Table 1. Univariate analysis

\begin{tabular}{|c|c|c|c|}
\hline Univariate analysis & Laparoscopic procedure & Laparoscopic converted to open & $\mathrm{p}$-value \\
\hline Number of patients & 122 & 39 & \\
\hline Age (y) & $41.51 \pm 22.3(4 \sim 89)$ & $52.74 \pm 15.97(13 \sim 79)$ & 0.0009 \\
\hline Age 45 years and older & $56(45.9)$ & $30(76.9)$ & 0.0007 \\
\hline Gender (male) & $67(54.9)$ & $23(59.0)$ & 0.6570 \\
\hline ASA class $=4$ & $3(2.5)$ & $1(2.6)$ & 1.0000 \\
\hline Septic & $61(50.0)$ & $25(64.1)$ & 0.1243 \\
\hline Perforated on CT & $17(13.9)$ & $13(33.3)$ & 0.0068 \\
\hline Onset of symptoms & $58(47.5)$ & $22(56.4)$ & 0.3349 \\
\hline \multicolumn{4}{|l|}{$\mathrm{Lab}$ value } \\
\hline WBC & $15.13 \pm 5.04(5.12 \sim 30.63)$ & $14.57 \pm 4.34(7.4 \sim 23.2)$ & 0.5277 \\
\hline WBC range & & & 0.9240 \\
\hline$<12$ & $35(28.7)$ & $10(25.6)$ & \\
\hline $12 \sim 20$ & $68(55.7)$ & $23(59.0)$ & \\
\hline$\geq 20$ & $18(14.8)$ & $6(15.4)$ & \\
\hline BiCarb & $25.59 \pm 2.78(17.5 \sim 31.3)$ & $25.06 \pm 3.27(16.4 \sim 30.4)$ & 0.3312 \\
\hline BiCarb range & & & 0.1277 \\
\hline$<20$ & $3(2.5)$ & $4(10.3)$ & \\
\hline $20 \sim 25$ & $41(33.6)$ & $12(30.8)$ & \\
\hline$\geq 25$ & $74(60.7)$ & $23(59.0)$ & \\
\hline Glucose & $126.46 \pm 52.23(63 \sim 443)$ & $138.36 \pm 57.81(70 \sim 372)$ & 0.2316 \\
\hline Glucose $\geq 100$ & $92(75.4)$ & $29(74.4)$ & 0.8948 \\
\hline Anion gap & $8.77 \pm 2.51 \quad(3.5 \sim 16)$ & $9.40 \pm 3.36(3.9 \sim 18.4)$ & 0.2915 \\
\hline Anion gap $\geq 12$ & $12(9.8)$ & $9(23.1)$ & 0.0326 \\
\hline Creatinine & $1.07 \pm 1.23(0.4 \sim 11)$ & $1.20 \pm 1.03(0.4 \sim 7.2)$ & 0.5634 \\
\hline Creatinine $\geq 1.3$ & $15(12.3)$ & $8(20.5)$ & 0.2017 \\
\hline CRP (mg/L) & $9.96 \pm 7.37(0.23 \sim 31.88)$ & $19.82 \pm 10.24(3.61 \sim 37.2)$ & $<0.0001$ \\
\hline \multicolumn{4}{|l|}{$\mathrm{CRP}$ range $(\mathrm{mg} / \mathrm{L})$} \\
\hline $1 \sim 5$ & $14(11.5)$ & $1(2.6)$ & 0.1301 \\
\hline $6 \sim 10$ & $19(15.6)$ & $4(10.3)$ & \\
\hline$\geq 11$ & $19(15.6)$ & $11(28.2)$ & \\
\hline Missing & $70(57.4)$ & $16(41.0)$ & \\
\hline \multicolumn{4}{|l|}{ Vital signs } \\
\hline Heart rate & $95.98 \pm 19.37 \quad(50 \sim 156)$ & $96.79 \pm 20.43(60 \sim 144)$ & 0.8208 \\
\hline Heart rate $\geq 100$ & $51(41.8)$ & $16(41.0)$ & 0.9737 \\
\hline Temperature & $37.18 \pm 0.76(35.1 \sim 39.7)$ & $37.29 \pm 0.91 \quad(35.4 \sim 39.6)$ & 0.4215 \\
\hline Temperature $\geq 38$ & $15(12.3)$ & $7(17.9)$ & 0.3709 \\
\hline MAP & $90.38 \pm 15.18(50 \sim 137)$ & $92.82 \pm 12.72(67 \sim 123)$ & 0.3654 \\
\hline MAP $<65$ & $5(4.1)$ & $0(0.0)$ & 0.3370 \\
\hline $\mathrm{RR}$ & $18.55 \pm 3.2(11 \sim 28)$ & $18.26 \pm 2.59(12 \sim 24)$ & 0.6048 \\
\hline $\mathrm{RR}>20$ & $84(68.9)$ & $25(64.1)$ & 0.5808 \\
\hline \multicolumn{4}{|l|}{ Risk factors } \\
\hline Hypertension & $35(28.7)$ & $18(46.2)$ & 0.0433 \\
\hline Hyperlipidemia & $25(20.5)$ & $10(25.6)$ & 0.4974 \\
\hline Diabetes mellitus & $11(9.0)$ & $8(20.5)$ & 0.0829 \\
\hline Coronary artery disease & $6(4.9)$ & $4(10.3)$ & 0.2571 \\
\hline Chronic kidney disease & $1(0.8)$ & $1(2.6)$ & 0.4269 \\
\hline Chronic obstructive pulmonary disorder & $2(1.6)$ & $1(2.6)$ & 0.5675 \\
\hline Previous pelvic surgery & $18(14.8)$ & $7(17.9)$ & 0.6316 \\
\hline Previous abdomen surgery & $13(10.7)$ & $5(12.8)$ & 0.7713 \\
\hline
\end{tabular}

Values are presented as number only, meantstandard deviation (range), or number (\%).

ASA: American Society of Anesthesiologists, CT: computed tomography, WBC: white blood cell, BiCarb: bicarbonate, CRP: c-reactive protein, MAP: mean arterial pressure, RR: respiratory rate. 
underwent previous abdominal or pelvic surgery compared to those that had had no previous abdominal surgery.

\section{4) Lab values}

Markers of acute infection and worsening metabolic status were reviewed for all patients including: WBC count, bicarbonate, glucose, creatinine, C-reactive protein (CRP) and anion gap. Of these markers both anion gap of greater than 12, which has classically been used as the lower limit of normal for a gapped acidosis, and CRP reach statistical significance. In $23.1 \%$ of LCO cases, the patient had an anion gap greater than 12 compared to only $9.8 \%$ of LA cases $(\mathrm{p}=0.0326)$. The mean CRP was 19.82 $\mathrm{mg} / \mathrm{L}$ in $\mathrm{LCO}$ case and $9.96 \mathrm{mg} / \mathrm{L}$ in $\mathrm{LA}$ case $(\mathrm{p}<0.0001)$. When comparing absolute values of CRP, $11.5 \%$ of LA cases and 2.6\% of LCO have a CRP between $1 \mathrm{mg} / \mathrm{L}$ and $5 \mathrm{mg} / \mathrm{L}(\mathrm{p}=0.1301)$ which then increases to $15.6 \%$ of LA and $28.2 \%$ of LCO for CRP of greater than $11 \mathrm{mg} / \mathrm{L}$, although this does not reach statistical significance. Although, in our patient population, 57.4\% of LA cases and $41.0 \%$ of LOC cases does not have a CRP drawn preoperatively.

\section{Multivariate analysis (Table 2)}

Those variables from the univariate analysis with a $\mathrm{p}$-value of $<0.1$ were then put through a multivariant analysis. In this model, age and preoperative CT reading of perforation both reached statistical significance. Age greater than 45 was 3.51 times more likely to undergo LCO procedure $(\mathrm{p}=0.0122)$. A preoperative CT read of perforation was 2.65 times more likely to undergo LCO $(\mathrm{p}=0.04502)$. An anion gap of 12 or more was approaching significance and associated with a 2.90 odds ratio (OR) of LCO.

Table 2. Multiple logistic regression on the risk factor for conversion

\begin{tabular}{lccc}
\hline \multicolumn{1}{c}{$\begin{array}{c}\text { Predict } \\
\text { variable }\end{array}$} & $\begin{array}{c}\text { Odds } \\
\text { ratio }\end{array}$ & $\begin{array}{c}95 \% \text { confidence } \\
\text { interval }\end{array}$ & p-value \\
\hline Age $\geq 45$ years & 3.51 & $1.31 \sim 9.39$ & 0.0122 \\
Perforated & 2.65 & $1.05 \sim 6.70$ & 0.0402 \\
Hypertension & 0.94 & $0.36 \sim 2.43$ & 0.8982 \\
Anion gap $\geq 12$ & 2.90 & $0.96 \sim 8.72$ & 0.0588 \\
Diabetes mellitus & 1.54 & $0.49 \sim 4.89$ & 0.4621 \\
\hline
\end{tabular}

\section{1) Surgical outcomes}

Postoperative abscess formation was 3.1\% among all groups. Amongst LA patients, two developed an abscess (1.67\%), both of which underwent successful placement of an intra-abdominal drain with interventional radiology. Three patients in the LCO cohort developed a postoperative abscess (7.89\%). Two patients had an intra-abdominal drain placed, only one of which was successful, the other required repeat laparoscopy and washout. The third patient's abscess was not accessible by interventional radiology and they required repeat laparoscopy and washout. Length of stay (LOS) was 3.44 days for the LA group while LCO was significantly longer at 6.1 days $(p<0.0001)$. During the longer hospitalization, $47.37 \%$ of LCO received additional imaging in the form of CT scans compared to $15.83 \%$ in the LA group $(p<0.0001)$. There was no statistically significant difference in 30-day emergency room visits or 30-day readmissions.

\section{Discussion}

Appendicitis remains the number one reason for acute intra-abdominal surgery. With the continued high incidence, increasing attention has been given to optimal management. Standard of care remains removal of the appendix operatively. As minimally invasive procedures continue to dominate the surgical landscape, completion of a LA has become the benchmark for procedural success. Advances in technology, as well as surgeon comfort, has eliminated indications for open appendectomy [1]. Patient populations such as the elderly, obese and those with abnormal anatomy, once only offered laparotomy, should now be attempted laparoscopically.

In addition to improved cosmetic outcome, LA has been associated with less postoperative pain and a shorter length of hospital stay. In the hands of an experienced surgeon it is also associated with fewer complications than in open appendectomy $[1,2]$. While proven to be safe in non-perforated cases it has recently been shown to be safe in perforated cases as well $[1,3,4]$. In a previous study, we found that in our institution $19.19 \%$ of cases of perforated appendicitis resulted in a need to convert from laparoscopic to an open procedure. This number was 
significantly higher than recent published work from Kim et al. [5], where a conversion rate of $11.8 \%$ was seen in cases of complicated appendicitis. In similar study examining causes of conversion to laparotomy in both simple and complicated appendicitis, a conversion rate of 7.9 was noted [6]. In an effort to better understand this high conversion rate, we looked at the preoperative characteristics of our patient population [7].

Risk factors such as: age greater than 55 , male gender and lower socioeconomic status has been previously implicated in complicated appendicitis [8]. In our study age was a risk factor for LCO, carrying the highest OR of 3.51. Due to the median age of our patients, we selected 45 as the our age cutoff, which does defer from previous work. While more of our patients were male, there was no correlation between gender and the type of procedure performed. In our patient population, univariate analysis of hypertension carried a higher tendency of LCO, which was not previously seen as a risk factor for perforation in other studies. Previous studies have shown that there is no correlation between onset of symptoms and perforation in the setting of appendicitis. Our study did not show time to emergency room from onset of symptoms to have any role in the procedure completed [9].

While standard laboratory studies were performed on most of the patients in this study, only anion gap was reviewed in the multivariant analysis with an OR of 2.90 approaching significance. Anion gap can indicate that the patient is becoming more acidotic from an underlying metabolic derangement. This calculation is easily performed with a basic metabolic panel which would part of almost all patients' preoperative laboratory evaluation. While we were unable to find another study directly evaluating anion gap, there is both adult and pediatric literature implicating hyponatremia as a marker for complicated appendicitis $[10,11]$. Hyponatremia would in theory lower the anion gap by increasing the minuend. In our analysis, elevated anion gap was predictive of failed LA in univariant analysis.

CRP was significant in the univariant analysis but was excluded from the multivariant analysis because of the high number of patients in which the test was not ordered. When CRP was ordered, the average amongst LCO cases was $19.82 \mathrm{mg} / \mathrm{L}$, which was significantly higher than in LA cases. While excluded from our analysis, significant elevation has been shown in all cases of appendicitis to be associated with conversion to an open procedure [6]. The average WBC count of both our LA and LCO cases was elevated, there was no difference seen when comparing intervention. Liver function studies, which have been reported as a risk factor, if complicated appendicitis, were not reviewed as few patients had this lab test performed.

CT scan is often used in the evaluation of abdominal pain and can accurately diagnosis appendicitis $95 \%$ of the time [12]. While accuracy of simple appendicitis is high, CT is far from perfect when identifying perforation with a specificity of $38 \%$ [13]. In addition, there is a discordance between surgeons, radiologists, and pathologists regarding the classification of perforation, which has been reported as high a $11.6 \%$ [14]. While CT misses many cases of perforation we found that when it is identified there is a 2.65 OR of a failed LA. CT has been proved as a safe and effective means of evaluating the appendix, and this study further demonstrates its utility in predicting a more difficult laparoscopic surgery.

As expected the LOS in the LA cohort was significantly shorter than LCO, which is one of the many benefits of minimally invasive surgery. In this study, successful completion of LA was associated with 2.6-day reduction in LOS. This reduction is comparable to a recent meta-analysis comparing LA to open appendectomy, which found a reduction of 2.47 days [15]. In a study by Dhupar et al. [16], the addition of just over two days was associated with an $86 \%$ higher average cost of the hospitalization. This cost was attributed to nursing and pharmacy cost, but we have shown this there was also an increase in the use of post-operative imaging. In our LCO cohort, $47.37 \%$ has a postoperative CT scan during their hospitalization. Postoperative CT can effectively and reliably identify an abscess as early as post-operative three [17], by waiting until day seven is associated with fewer drainage procedures without increasing readmission rates [18]. While it is unclear why, it can be seen that the attending surgeon was more likely to proceed to postoperative imaging in the LCO group than the LA cohort, even when evidence shows that it is unnecessary.

There are areas where this study can be improved. As a retrospective chart review, there is a risk of inherent bias due to study design. Also as a chart review, human error in charting 
is possible. The lack of complete lab work, as well as imaging in all patients, also may have affected our results. A prospective trial, with standardized preoperative orders for all patients with right lower quadrant pain and suspected appendicitis would be a way to further improve our results.

Operative planning is essential to procedural success. Our study identifies clear preoperative risk factors for need to conversion to laparotomy during a planned laparoscopic procedure. We believe that these risk factors should not influence the decision to attempt laparoscopy, as a minimally invasive approach in our study is associated with a short LOS and has been shown in multiple studies to have decreased pain and shorter return to normal daily activities. Rather these risk factors should be taken into account when counseling patients preoperatively and in preoperative planning.

Patients older than 45 years old with a CT radiologist read of perforation in multivariant analysis are associated with increased risk of failed laparoscopic surgery requiring conversion to open surgery.

\section{Conflicts of Interest}

No potential conflict of interest relevant to this article was reported.

\section{References}

1. Popa D, Soltes M, Uranues S, Fingerhut A. Are there specific indications for laparoscopic appendectomy? A review and critical appraisal of the literature. J Laparoendosc Adv Surg Tech A 2015;25:897-902.

2. Galli R, Banz V, Fenner H, Metzger J. Laparoscopic approach in perforated appendicitis: increased incidence of surgical site infection? Surg Endosc 2013;27:2928-33.

3. Gomes CA, Junior CS, Costa Ede F, Alves Pde A, de Faria $\mathrm{CV}$, Cangussu IV, et al. Lessons learned with laparoscopic management of complicated grades of acute appendicitis. J Clin Med Res 2014;6:261-6.

4. Wei HB, Huang JL, Zheng ZH, Wei B, Zheng F, Qiu WS, et al. Laparoscopic versus open appendectomy: a prospective randomized comparison. Surg Endosc 2010;24:266-9.

5. Kim JK, Kang J, Kim WR, Park EJ, Baik SH, Lee KY. Does conversion adversely impact the clinical outcomes for patients with complicated appendicitis? J Laparoendosc Adv Surg Tech A 2016;26:635-40.

6. Antonacci N, Ricci C, Taffurelli G, Monari F, Del Governatore M, Caira A, et al. Laparoscopic appendectomy: which factors are predictors of conversion? A high-volume prospective cohort study. Int J Surg 2015;21:103-7.

7. Abe T, Nagaie T, Miyazaki M, Ochi M, Fukuya T, Kajiyama $\mathrm{K}$. Risk factors of converting to laparotomy in laparoscopic appendectomy for acute appendicitis. Clin Exp Gastroenterol 2013;6:109-14.

8. Augustin T, Cagir B, Vandermeer TJ. Characteristics of perforated appendicitis: effect of delay is confounded by age and gender. J Gastrointest Surg 2011;15:1223-31.

9. Nazarey PP, Stylianos S, Velis E, Triana J, Diana-Zerpa J, Pasaron R, et al. Treatment of suspected acute perforated appendicitis with antibiotics and interval appendectomy. J Pediatr Surg 2014;49:447-50.

10. Pham XD, Sullins VF, Kim DY, Range B, Kaji AH, de Virgilio CM, et al. Factors predictive of complicated appendicitis in children. J Surg Res 2016;206:62-6.

11. Kim DY, Nassiri N, de Virgilio C, Ferebee MP, Kaji AH, Hamilton CE, et al. Association between hyponatremia and complicated appendicitis. JAMA Surg 2015;150:911-2.

12. Bendeck SE, Nino-Murcia M, Berry GJ, Jeffrey RB Jr. Imaging for suspected appendicitis: negative appendectomy and perforation rates. Radiology 2002;225:131-6.

13. Verma R, Grechushkin V, Carter D, Barish M, Pryor A, Telem D. Use and accuracy of computed tomography scan in diagnosing perforated appendicitis. Am Surg 2015;81:404-7.

14. Farzal Z, Farzal Z, Khan N, Fischer A. The diagnostic dilemma of identifying perforated appendicitis. J Surg Res 2015;199:164-8

15. Yu MC, Feng YJ, Wang W, Fan W, Cheng HT, Xu J. Is laparoscopic appendectomy feasible for complicated appendicitis? A systematic review and meta-analysis. Int J Surg 2017; 40:187-97.

16. Dhupar R, Evankovich J, Ochoa JB, Vargas LG, Hughes SJ. Outcomes of operative management of appendicitis. Surg Infect (Larchmt) 2012;13:141-6.

17. Antevil JL, Egan JC, Woodbury RO, Rivera L, Oreilly EB, Brown CV. Abdominal computed tomography for postoperative abscess: is it useful during the first week? J Gastrointest Surg 2006;10:901-5.

18. Nielsen JW, Kurtovic KJ, Kenney BD, Diefenbach KA. Postoperative timing of computed tomography scans for abscess in pediatric appendicitis. J Surg Res 2016;200:1-7. 